\title{
An electrochemical immunosensor based on a 4,4'- thiobisbenzenethiol self-assembled monolayer for the detection of hemagglutinin from avian influenza virus H5N1
}

\author{
Urszula Jarocka $^{\text {a }}$, Róża Sawicka ${ }^{\text {b }}$, Anna Góra-Sochacka ${ }^{\text {b }}$, Agnieszka Sirko ${ }^{\text {b }}$, Wim \\ Dehaen ", Jerzy Radecki a , Hanna Radecka ${ }^{\text {a,* }}$ \\ a Institute of Animal Reproduction and Food Research, Polish Academy of Sciences, Tuwima 10, 10- \\ 748 Olsztyn, Poland \\ ${ }^{\mathrm{b}}$ Institute of Biochemistry and Biophysics, Polish Academy of Sciences, Pawińskiego 5A, 02-106 \\ Warsaw, Poland \\ ${ }^{c}$ University of Leuven, Department of Chemistry, Celestijnenlaan 200F, B-3001 Leuven, Belgium
}

* Corresponding authors. Tel.: +48-89-523-4636; Fax: +48-89-524-0124.

E-mail address: h.radecka@pan.olsztyn.pl.

\begin{abstract}
An electrochemical immunosensor for the detection of hemagglutinin from avian influenza virus $\mathrm{H} 5 \mathrm{~N} 1$ is presented in this paper. The following steps lead up to the construction of immunosensor: (i) modification of gold electrodes with 4,4'-thiobisbenzenethiol, (ii) modification of self-assembled monolayer of 4,4'-thiobisbenzenethiol with gold colloidal nanoparticles, (iii) immobilization of single chain variable fragments of antibodies $(\mathrm{scFv})$ against hemagglutinin H5 via S-Au covalent bonds, (iv) blocking of the remaining free space with bovine serum albumin. The interactions between the $\mathrm{scFv}$ and hemagglutinin variants have been explored with electrochemical impedance spectroscopy in the presence of $\left[\mathrm{Fe}(\mathrm{CN})_{6}\right]^{3-14-}$ as an electroactive marker. The immunosensor was able to detect two different His-tagged variants of recombinant hemagglutinin from $\mathrm{H} 5 \mathrm{~N} 1$ viruses: the short fragment (17-340 residues) of A/swan/Poland/305-135V08/2006 and the long (17-530 residues) of A/Bar-headed Goose/Qinghai/12/2005. The strongest response has been observed for the long variant with a detection limit of $0.6 \mathrm{pg} / \mathrm{mL}$ and a dynamic range from 4.0 to $20.0 \mathrm{pg} / \mathrm{mL}$. The recombinant hemagglutinin (17-527 residues) from A/chicken/Netherlands/1/03 (H7N7),
\end{abstract}


used as the negative control generated a weak response. This confirms the selectivity of the immunsensor proposed. A miniaturized version of the immunosensor, based on screenprinted gold electrodes, was tested with the same set of recombinant hemagglutinins and it achieved a linear range from 1 to $8 \mathrm{pg} / \mathrm{mL}$ with a detection limit of $0.9 \mathrm{pg} / \mathrm{mL}$ for the long fragment of hemagglutinin.

Keywords: 4,4'-Thiobisbenzenethiol, Avian influenza virus, $\mathrm{scFv}$ antibody fragments, Screen-printed gold electrodes, Miniaturization, Electrochemical impedance spectroscopy

\section{Introduction}

Highly pathogenic avian influenza viruses (HPAIVs) cause huge economic losses in the poultry industry around the world. Hundreds of millions of domestic birds have died as a result of infection and during culling activities to control the spread of epidemics. Furthermore the virus has posed a potential risk for transmission to humans. Rapid and specific detection of avian influenza virus (AIV) is urgently needed due to the concerns over the potential outbreaks [1,2].

Electrochemical immunosensors, based on the highly biospecific recognition interaction between antigen and antibodies, have recently aroused much interest for the fast and sensitive detection of a target antigen [3-5]. In most cases, the key element is the quality of the antibody used. Advances in antibody gene cloning and expression have led to the development of recombinant antibodies, comprising the binding fragments of antibody molecules such as antibody-binding fragments (Fab') and single chain variable fragments (scFv). Recombinant $\mathrm{scFv}$ is a small $(\sim 25 \mathrm{kDa})$ protein composed of antibody variable heavy (VH) and light (VL) chains that are connected by a peptide linker [6]. The key advantage of using a $\mathrm{scFv}$ as a recognition element is its excellent selectivity to the antigen and the low production costs $[7,8]$.

Nowadays, the design of an electrochemical sensor has been developed in the field of electrochemistry to improve the analytical efficiency in terms of sensitivity, selectivity, reliability, low cost, ease of fabrication and use [9]. The advent of screen-printing technology has provided new exciting opportunities to apply electrochemical techniques for analyses outside a centralised laboratory. Generally, screen-printed electrodes (SPEs) are made on plastic or ceramic substrates where working, counter and reference electrodes are printed $[10,11]$. They are commercially available and they present a great versatility, because they 
can be manufactured depending on the application. They can be connected to a portable potentiostat and can be operated in static mode (drop sensor), hydrodynamic mode (common electrochemical cell) or in flow systems. The SPEs offer a number of advantages versus conventional electrodes such as the possibility for miniaturization, the low costs of mass production, and their portable and disposable nature [12]. They have been successfully used as electrochemical sensors in various studies [9,13-15].

Here, we present a construction of a novel type of an electrochemical immunosensor and demonstrate its suitability for the detection of $\mathrm{H} 5$ hemagglutinin from avian influenza virus. 4,4'-Thiobisbenzenethiol (TBBT) was used for the creation of a self-assembled monolayer (SAM) suitable for gold nanoparticles deposition and covalent immobilization of scFv antibody fragments [16]. The specificity of immunosensor is determined by the specificity of the used antibody fragment. Interactions between scFv immobilized on the surface of gold disc electrodes (GDEs) and two His-tagged variants of recombinant hemagglutinin from A/swan/Poland/305-135V08/2006 (H5N1) and A/Bar-headed Goose/Qinghai/12/2005 (H5N1) were observed using electrochemical impedance spectroscopy (EIS) and Osteryoung square-wave voltammetry (OSWV) in the presence of $\left[\mathrm{Fe}(\mathrm{CN})_{6}\right]^{3-14-}$ as an electroactive marker. In addition, this analytical device was miniaturized using screen-printed gold electrodes (SPGEs).

\section{Experimental}

\subsection{Reagents and materials (see Supporting Information)}

\subsection{Preparation of the immunosensor based on the gold disc electrodes (see Supporting Information)}

\subsection{Preparation of the immunosensor based on the screen-printed gold electrodes}

The disposable screen-printed gold electrodes (SPGEs) were purchased from DropSens (Oviedo, Spain). They are designed in a conventional three electrode configuration printed on the same strip. The dimensions of the strips are $3.4 \times 10 \times 0.05 \mathrm{~cm}$ (length $\times$ weight $\times$ height), where both the working ( $4 \mathrm{~mm}$ diameter) and the counter electrodes are made of gold, whereas the reference electrode and electric contacts are made of silver. An insulating layer serves to delimit the working area and silver electric contacts.

The SPGEs were washed with Milli-Q water and cleaned electrochemically by Cyclic Voltammetry $(\mathrm{CV})$. They were dipped in $0.5 \mathrm{M}$ sulphuric acid solution and swept with a potential between $-0.2 \mathrm{~V}$ and $1.1 \mathrm{~V}$ with scan rate of $0.1 \mathrm{~V} / \mathrm{s}$, number of cycles: 3, 50 and 10 . 
The clean SPGEs were washed repeatedly with Milli-Q water, ethanol and immersed in a cell in Teflon for screen-printed electrodes (DropSens, Oviedo, Spain). Then, $20 \mu \mathrm{L}$ of $1 \mathrm{mM}$ TBBT in ethanol were dropped onto the surface of each working electrode. The cells containing the electrodes and TBBT were sealed with parafilm to avoid solvent evaporation and stored for $0.5 \mathrm{~h}$. After incubation, the electrodes were rinsed with ethanol, Milli-Q water and next $10 \mu \mathrm{L}$ of AuNPs were dropped onto the gold surfaces for $2 \mathrm{~h}$. Subsequently the electrodes were rinsed with Milli-Q water and 0.1 M PBS, $\mathrm{pH}$ 7.4. Then $10 \mu \mathrm{L}$ droplets of 1 $\mu \mathrm{g} / \mathrm{mL} \mathrm{scFv}$ in PBS buffer were spotted onto the surface of each electrode and incubated for $1 \mathrm{~h}$. Next, the electrodes were carefully rinsed with PBS buffer. BSA was used for the blocking of any unspecific binding. As in the prior steps, $10 \mu \mathrm{L}$ of $1 \%$ BSA were dropped on each electrode and this was stored for $0.5 \mathrm{~h}$. Finally, the electrodes were rinsed with $0.1 \mathrm{M}$ PBS and kept in a refrigerator $\left(+4^{\circ} \mathrm{C}\right)$ in $0.1 \mathrm{M}$ PBS buffer until use, no longer than one day unless stated otherwise.

2.4. The specific interaction between $s c F v$ and His-tagged recombinant hemagglutinin variants

"Qinghai", "HA/Nde" and "Netherlands" were diluted in the buffer (0.1 M PBS, pH 7.4) to the concentration of $4,8,12,16,20 \mathrm{pg} / \mathrm{mL}$ for the GDEs and $1,4,8 \mathrm{pg} / \mathrm{mL}$ for the SPGEs, respectively. The reactions between the $\mathrm{scFv}$ and the His-tagged recombinant hemagglutinin variants were performed by dropping of $10-\mu \mathrm{L}$ aliquots of the respective concentrations of the antigens on the $\mathrm{BSA} / \mathrm{scFv} / \mathrm{AuNPs} / \mathrm{TBBT} / \mathrm{Au}$ modified electrode surfaces. The GDEs were covered by Eppendorf tubes and the SPGEs were kept in the cell in order to protect against evaporation and air pollution. After $0.5 \mathrm{~h}$ of incubation at room temperature, the electrodes were rinsed with $5 \mathrm{~mL}$ of $0.1 \mathrm{M} \mathrm{PBS}$, at $\mathrm{pH} 7.4$ in order to remove the unbound antigens.

\subsection{Electrochemical measurements (see Supporting Information)}

\section{Results and Discussion}

\subsection{Fabrication of the immunosensor-successive steps of electrode modification}

Scheme 1 illustrates the process of immunosensor construction. Gold electrodes, after cleaning, were coated with TBBT. The structure of TBBT SAMs on Au has been investigated by surface enhanced Raman scattering (SERS), electrochemical CV, EIS, and atomic force microscopy (AFM) [17]. TBBT adsorbed on the electrode surface by losing a $\mathrm{H}$ atom, 
forming one Au-S bond, and the other mercapto group is free at the surface of the monolayer owing to the presence of the $v S-H$ at $2513 \mathrm{~cm}^{-1}$ and the $\delta \mathrm{C}-\mathrm{S}-\mathrm{H}$ at $910 \mathrm{~cm}^{-1}$ in SERS. The enhancement of the vibration of C-S $\left(1064 \mathrm{~cm}^{-1}\right)$, the aromatic C-H vibration $\left(3044 \mathrm{~cm}^{-1}\right)$, and the absence of the vibration of S-S illustrate TBBT adsorbed on Au forming a monolayer with one benzene ring tilted with respect to the Au surface. AFM of TBBT exhibits a clustered surface morphology with irregularly shaped islands covering the surface measuring from 1 to $5 \mathrm{~nm}$. Zooming in to view the surface indicates surface roughness of about $0.5 \mathrm{~nm}$, which demonstrates the monolayer of TBBT. Because $S$ between the two phenyl groups presents a sp3 hybridization, the angle between the two phenyl groups must be about $110^{\circ}$. [17]. Next, a AuNPs layer was formed via covalent Au-S bonds. Then, scFv was deposited onto the colloidal gold layer, also through $\mathrm{Au}-\mathrm{S}$ bonds. At the $\mathrm{N}$-end of scFv thioredoxin has been attached. Thioredoxin is a $12-\mathrm{kD}$ oxidoreductase enzyme containing a dithiol-disulfide active site. BSA was used to block any possible remaining active sites against non-specific adsorption on the electrode surfaces.

\section{Please insert here Scheme 1}

Each step of the GDEs modification was controlled using CV (Fig. S1 in Supporting Information) and EIS (Fig. S2 in Supporting Information) in the presence of $1.0 \mathrm{mM}$ $\mathrm{K}_{3}\left[\mathrm{Fe}(\mathrm{CN})_{6}\right] / \mathrm{K}_{4}\left[\mathrm{Fe}(\mathrm{CN})_{6}\right](1: 1)$ as redox marker in 0.1 M PBS pH 7.4. The bare GDEs have no obstacles affecting electron transfer which results in $\mathrm{CV}$ peak separation $\Delta \mathrm{E}_{\mathrm{p}}=75 \mathrm{mV}$ (Fig. S1, curve a) and an almost straight line in the Nyquist plot (Fig. S2, curve a). These indicate a diffusion controlled electrochemical process. The covalent attachment of TBBT on the GDEs surfaces reduced the accessibility of the redox marker to the electrode surfaces. This increased the CV peak separation to $\Delta \mathrm{E}_{\mathrm{p}}=361 \mathrm{mV}$ (Fig. S1, curve b) and the electron transfer resistance to $R_{\mathrm{et}}=425.4 \mathrm{k} \Omega$ (Fig. S2, curve b). The chemisorption of AuNPs on the TBBT layer caused an increase of the conduction pathways and promoted the electron transfer between the redox marker and electrode surface. As the result AuNPs decreased the $\mathrm{CV}$ peak separation to $\Delta \mathrm{E}_{\mathrm{p}}=120 \mathrm{mV}$ (Fig. S1, curve c) and the electron transfer resistance to $\mathrm{R}_{\mathrm{et}}=75.3 \mathrm{k} \Omega$ (Fig. S2, curve c). The immobilization of $\mathrm{scFv}$ on the colloidal gold layer formed an insulating layer and decreased the accessibility of $\left[\mathrm{Fe}(\mathrm{CN})_{6}\right]^{3-/ 4-}$. This caused an increase of the $\mathrm{CV}$ peak separation to $\Delta \mathrm{E}_{\mathrm{p}}=156 \mathrm{mV}$ (Fig. $\mathrm{S} 1$, curve d) and the electron transfer resistance to $\mathrm{R}_{\mathrm{et}}=159.0 \mathrm{k} \Omega$ (Fig. S2, curve d). Further decreasing of the CV peak separation to $\Delta E_{p}=244 \mathrm{mV}$ (Fig. S1, curve e) and the electron transfer resistance to $R_{e t}=$ 
$382.7 \mathrm{k} \Omega$ (Fig. S2, curve e) were observed upon immobilization of BSA onto the remaining sites on the gold layer.

Successive fabrication steps of the SPGEs modification were controlled using CV (Fig. S3 in Supporting Information) and OSVW (Fig. S4 in Supporting Information) in the presence of $1.0 \mathrm{mM} \mathrm{K}_{3}\left[\mathrm{Fe}(\mathrm{CN})_{6}\right] / \mathrm{K}_{4}\left[\mathrm{Fe}(\mathrm{CN})_{6}\right](1: 1)$ as redox marker in 0.1 M PBS pH 7.4. The bare SPGEs had the CV peak separation $\Delta \mathrm{E}_{\mathrm{p}}=90 \mathrm{mV}$ (Fig. S3, curve a) and the peak current $\mathrm{I}=12.3 \mu \mathrm{A}$ in OSWV (Fig. S4, curve a). After the covalent attachment of TBBT on the electrode surfaces the CV peak separation increased to $\Delta \mathrm{E}_{\mathrm{p}}=198 \mathrm{mV}$ (Fig. S3, curve b) and the peak current in OSWV decreased to $\mathrm{I}=3.4 \mu \mathrm{A}$ (Fig. S4, curve b). The chemisorption of AuNPs on the TBBT layer decreased the CV peak separation increased to $\Delta \mathrm{E}_{\mathrm{p}}=102 \mathrm{mV}$ (Fig. S3, curve c) and increased the peak current in OSWV to I $=9.5 \pm 10 \mu \mathrm{A}$ (Fig. S4, curve c). The immobilization of scFv on AuNPs layer caused an increase of the CV peak separation to $\Delta \mathrm{E}_{\mathrm{p}}=161 \mathrm{mV}$ (Fig. S3, curve d) and a decrease of the peak current in OSWV to $\mathrm{I}=3.9$ $\mu \mathrm{A}$ (Fig. S4, curve d). Blocking the remaining sites of the colloidal gold layer with BSA increased the CV peak separation to $\Delta \mathrm{E}_{\mathrm{p}}=215 \mathrm{mV}$ (Fig. S3, curve e) and decreased the peak current in OSWV to $\mathrm{I}=2.4 \mu \mathrm{A}$ (Fig. S4, curve c).

\subsection{Detection of His-tagged recombinant hemagglutinin variants of H5N1 virus with gold} disc electrodes

Quantitative assessment of the sensitivity of the immunosensor based on GDEs was done with serial dilutions of two different His-tagged recombinant variants of H5 hemagglutinin: "Qinghai" and "HA/Nde" in PBS buffer, $\mathrm{pH}$ 7.4. Typical responses of the immunosensor registered using EIS are shown in Fig. 1. Electron transfer resistance measured for the immunosensor in PBS buffer before antigens detection $\mathrm{R}_{0}$ (Fig.1, curve a) was used to calculate the relative response towards a specific variant of hemagglutinin. Interactions between $\mathrm{scFv}$ and recombinant $\mathrm{H} 5$ hemagglutinins caused decreased accessibility of the redox marker $\left[\mathrm{Fe}(\mathrm{CN})_{6}\right]^{3-/ 4-}$ to the GDEs surface. As a result we observed a rise of the electron transfer resistance $R_{i}$ with addition of increasing concentrations of the antigen (Fig. 1, curves b-f). The negative control ("Netherlands") generated a weak response (Fig. 1B), which confirmed the selectivity of the immunsensor.

Please insert here Fig. 1 
The highest concentration of antigen $(20 \mathrm{pg} / \mathrm{mL})$ caused a significant increase of the electron transfer resistance to $84.6 \pm 4.7 \%$ for "Qinghai" and $60.0 \pm 3.6 \%$ for "HA/Nde" (Fig. 2). A linear range of the analytical response was observed from 4 to $20 \mathrm{pg} / \mathrm{mL}$. The limit of detection (LOD) was calculated using the equation: $\mathrm{LOD}=3.3 \sigma / S$ where $\sigma$ is the standard deviation of the response and $\mathrm{S}$ is the slope of the calibration curve [18]. The LOD was $0.6 \mathrm{pg} / \mathrm{mL}$ for "Qinghai" and $2.1 \mathrm{pg} / \mathrm{mL}$ for "HA/Nde". The negative control ("Netherlands") generated a negligible response. In the presence of the highest concentration $(20 \mathrm{pg} / \mathrm{mL})$ of "Netherlands" only a $6.5 \pm 1.7 \%$ increase of the electron transfer resistance was observed (Fig. 2).

Please insert here Fig. 2

In our previous paper [19], we have described an impedimetric immunosensor for the detection of "Qinghai" and "HA/Nde". Its preparation consists of successive modification steps of gold electrodes: (i) modification with 1,6-hexanedithiol and gold colloidal nanoparticles, (ii) immobilization of antibody-binding fragments (Fab') of anti-hemagglutinin H5 monoclonal antibodies Mab 6-9-1 via S-Au covalent bonds, (iii) filling any free space with BSA. The interactions between the Fab' fragments and antigens have been explored with EIS in the presence of $\left[\mathrm{Fe}(\mathrm{CN})_{6}\right]^{3-/ 4-}$ as an electroactive marker. LODs were $2.2 \mathrm{pg} / \mathrm{mL}$ for "Qinghai" and $4.0 \mathrm{pg} / \mathrm{mL}$ for "HA/Nde". The device presented in this paper has better sensitivity. The Au / TBBT layer was more reproducible and stable in comparison to the $\mathrm{Au} /$ HDT layer. The electron transfer resistance of the $\mathrm{Au} / \mathrm{TBBT}$ layer $\left(\mathrm{R}_{\mathrm{et}}=425.4 \mathrm{k} \Omega\right)$ was much lower than for the $\mathrm{Au} / \mathrm{HDT}$ layer $\left(\mathrm{R}_{\mathrm{et}}=1359.3 \mathrm{k} \Omega\right.$ ) (Fig. S5 in Supporting Information). Moreover, the immunosensor proposed here had a shorter time of modification and a four times lower detection limit than the one already reported [19].

\subsection{Detection of His-tagged recombinant hemagglutinin variants of H5N1 virus with screen- printed gold electrodes - miniaturisation}

An immunosensor based on SPGEs was applied for screening of the interactions between the $\mathrm{scFv}$ attached to the electrode surface and different recombinant hemagglutinin variants present in the sample solution using OSWV. Representative square wave voltammograms recorded in the presence of "Qinghai" and "Netherlands" are presented in Fig. 3. 
Please insert here Fig. 3

Upon increasing the concentration of "Qinghai" and "HA/Nde", a decrease of the peak current was observed. The highest concentration of "Qinghai" and "HA/Nde" (8 pg/mL) caused $64.0 \pm 1.8 \%$ and $53.1 \pm 4.2 \%$ decrease of peak current, respectively. In the presence of $20 \mathrm{pg} / \mathrm{mL}$ of "Netherlands" only $1.5 \pm 2.8 \%$ decrease of peak current was observed (Fig. 4). The current values used in Fig 4 were taken from the experiment described in Fig 3. The LODs for the "Qinghai' and "HA/Nde" were $0.9 \mathrm{pg} / \mathrm{mL}$ and $1.7 \mathrm{pg} / \mathrm{mL}$, respectively.

Please insert here Fig. 4

In the next step, the stability over time of the immunosensor based on SPGEs was controlled. Fully modified SPGEs were kept in refrigerator $\left(+4^{\circ} \mathrm{C}\right)$ in $0.1 \mathrm{M} \mathrm{PBS}$ buffer, pH 7.4 for one week. Next, the electrodes were used for the detection of "Qinghai". The highest concentration of "Qinghai” ( $8 \mathrm{pg} / \mathrm{mL})$ caused $57.2 \pm 7.8 \%(\mathrm{n}=5)$ decrease of peak current. This value is only $10 \%$ lower than the response of immunosensor recorded one day after its preparation.

Please insert here Table 1

Considering different parameters, such as sensitivity, selectivity and simplicity of sensor preparation, the biosensor presented in this work is superior to numerous immunosensors already reported (Table 1). Most of the devices reported in the literature for biosensing applications have not been tested with real biological samples. It is worth to emphasize that the main advantages of the device proposed here are its simple fabrication, its demand of only a small sample volume and its disposable nature. Moreover, due to miniaturization, the use of our device is not limited to the laboratory conditions.

\section{Conclusions}

4,4'-Thiobisbenzenethiol (TBBT) SAM deposited on the gold surface possess a superior parameters in regards to reproducibility and stability, as well as the three times lower electron transfer resistance in the comparison to 1,6-hexanedithiol (HDT) SAM. The TBBT SAM was suitable for covalent deposition of colloidal gold nanoparticles, which 
function as excellent environment for $\mathrm{scFv}$ immobilization. Such modification was the base of a sensitive and selective electrochemical immunosensor for the detection of peptides hemagglutinin from avian influenza viruses. This device is capable to recognize two Histagged variants of $\mathrm{H} 5$. The strongest response was observed for the longer variant (“Qinghai") with a detection limit of $0.6 \mathrm{pg} / \mathrm{mL}$ and dynamic range from $4.0 \mathrm{pg} / \mathrm{mL}$ to 20.0 $\mathrm{pg} / \mathrm{mL}$. A negative control (H7 hemagglutinin), generated only a weak response. The miniaturized system was able to detect "Qinghai" with a detection limit of $0.9 \mathrm{pg} / \mathrm{mL}$. Therefore, this could be the method of choice for the rapid, simple and direct electrochemical detection of H5 hemagglutinin from influenza virus in the field conditions. One should also remember that the specificity of immunosensor is strongly affected by the properties (antigen affinity and cross-reactivity) of antibody used for immunosensor fabrication.

\section{Acknowledgments}

This work was supported by the Innovative Economy Program, No. WNDPOIG.01.01.02-00-007/08 and the Institute of Animal Reproduction and Food Research of Polish Academy of Sciences, Olsztyn, Poland. Wim Dehaen thanks the University of Leuven, the FWO-Vlaanderen and the Ministerie voor Wetenschapsbeleid for financial support.

\section{References}

1. J. Lin, R. Wang, P. Jiao, Y. Li, Y. Li, M. Liao, Y. Yu, M. Wang, An impedance immunosensor based on low-cost microelectrodes and specific monoclonal antibodies for rapid detection of avian influenza virus $\mathrm{H} 5 \mathrm{~N} 1$ in chicken swabs, Biosens. Bioelectron. 67 (2015) 546-552.

2. H. Bai, R. Wang, B. Hargis, H. Lu, Y. Li, A SPR Aptasensor for detection of avian influenza virus H5N1, Sensors 12 (2012) 12506-12518.

3. E.B. Bahadir, M.K. Sezgintürk, Applications of electrochemical immunosensors for early clinical diagnostics, Talanta (132) 2015 162-174.

4. L. Krejcova, D. Hynek, P. Michalek, V. Milosavljevic, P. Kopel, O. Zitka, M. Konecna, J. Kynicky, V. Adam, J. Hubalek, R. Kizek, Electrochemical sensors and biosensors for influenza detection - literature survey 2012-2013, Int. J. Electrochem. Sci. 9 (2014) 3440-3448. 
5. U. Jarocka, R. Sawicka, A. Góra-Sochacka, A. Sirko, W. Zagórski-Ostoja, J. Radecki, H. Radecka, Electrochemical immunosensor for detection of antibodies against influenza A virus H5N1 in hen serum, Biosens. Bioelectron. (55) 2014 301-306.

6. B. Kim, D. Lim, H.J. Jin, H.Y. Lee, S. Namgung, Y. Ko, S.B. Park, S. Hong, Familyselective detection of antibiotics using antibody-functionalized carbon nanotube sensors, Sens. Actuators B 166-167 (2012) 193-199. P.D.

7. Skottrup, M. Nicolaisen, A.F. Justesen, Towards on-site pathogen detection using antibody-based sensors, Biosens. Bioelectron. 24 (2008) 339-348.

8. L. Torrance, A. Ziegler, H. Pittman, M. Paterson, R. Toth, I. Eggleston, Oriented immobilisation of engineered single-chain antibodies to develop biosensors for virus detection, J. Virol. Meth. 134 (2006) 164-170.

9. K. Charoenkitamorn, O. Chailapakul, W. Siangproh, Development of gold nanoparticles modified screen-printed carbon electrode for the analysis of thiram, disulfiram and their derivative in food using ultra-high performance liquid chromatography, Talanta 132 (2015) 416-423.

10. H. Wan, Q. Sun, H. Li, F. Sun, N. Hu, P. Wang, Screen-printed gold electrode with gold nanoparticles modification for simultaneous electrochemical determination of lead and copper, Sens. Actuators B 209 (2015) 336-342.

11. E. Bernalte, C.M. Sánchez, E.P. Gil, Determination of mercury in ambient water samples by anodic stripping voltammetry on screen-printed gold electrodes, Anal. Chim. Acta 689 (2011) 60-64.

12. R. García-González, M.T. Fernández-Abedul, A. Pernía, A. Costa-García, Electrochemical characterization of different screen-printed gold electrodes, Electrochim. Acta 53 (2008) 3242-3249.

13. S. Sakthinathan, S. Palanisamy, S.-M. Chen, P.-S. Wu, L. Yao, B.-S. Lou, Electrochemical detection of phenol in industrial pollutant absorbed molecular sieves by electrochemically activated screen printed carbon electrode, Int. J. Electrochem. Sci. 10 (2015) 3319-3328.

14. F.A., C. Zanardi, S. Cinti, F. Terzi, D. Moscone, G. Palleschi, R. Seeber, Effective electrochemical sensor based on screen-printed electrodes modified with a carbon black-Au nanoparticles composite, Sens. Actuators B 212 (2015) 536-543.

15. S. Palanisamy, Ch. Karuppiah, S.-M. Chen, P. Periakaruppan, Highly sensitive and selective amperometric nitrite sensor based on electrochemically activated graphite modified screen printed carbon electrode, J. Electroanal. Chem. 727 (2014) 34-38. 
16. Patent application no: P-413 262“, Monoclonal antibodies, exchangeable parts of monoclonal antibodies and their applications, immunosensor and way of fabrication of immunosensor for detection of virus H5N1 (2015).

17. Y. Wang, L. Gan, H. Chen, S. Dong, J. Wang, Structure and identity of 4,4'thiobisbenzenethiol self-assembled monolayers, J. Phys. Chem. B 110 (2006) 2041820425.

18. M.E. Swartz, I.S. Krull, Handbook of analytical validation, third ed., CRC Press Taylor \& Francis Group: Boca Raton, FL, USA, 2012; p. 70.

19. U. Jarocka, R. Sawicka, A. Góra-Sochacka, A. Sirko, W. Zagórski-Ostoja, J. Radecki, H. Radecka, An immunosensor based on antibody binding fragments attached to gold nanoparticles for the detection of peptides derived from avian influenza hemagglutinin H5, Sensors 14 (2014) 15714-15728.

20.Z.-H. Yang, Y. Zhuo, R. Yuan, Y.-Q. Chai, An amplified electrochemical immunosensor based on in situ-produced 1-naphthol as electroactive substance and graphene oxide and $\mathrm{Pt}$ nanoparticles functionalized $\mathrm{CeO}_{2}$ nanocomposites as signal enhancer, Biosens. Bioelectron. 69 (2015) 321-327.

21. Z. Wu, Ch.-H. Zhou, J.-J. Chen, Ch. Xiong, Z. Chen, D.-W. Pang, Z.-L. Zhang, Bifunctional magnetic nanobeads for sensitive detection of avian influenza A (H7N9) virus based on immunomagnetic separation and enzyme-induced metallization, Biosens. Bioelectron. 68 (2015) 586-592.

22. C.-H. Zhou, Y.-M. Long, B.-P. Qi, D.-W. Pang, Z.-L. Zhang, A magnetic bead-based bienzymatic electrochemical immunosensor for determination of $\mathrm{H} 9 \mathrm{~N} 2$ avian influenza virus, Electrnochem. Commun. 31 (2013) 129-132. S.E.

23. Diltemiz, A. Ersöz, D. Hür, R. Keçili, R. Say, 4-Aminophenyl boronic acid modified gold platforms for influenza diagnosis, Mater. Sci. Eng. 33 (2013) 824-830.

24. W.M. Hassen, V. Duplan, E. Frost, J.J. Dubowski, Quantitation of influenza A virus in the presence of extraneous protein using electrochemical impedance spectroscopy, Electrochim. Acta 56 (2011) 8325-8328.

25. T.M.P. Hewa, G.A. Tannock, D.E. Mainwaring, S. Harrison, J.V. Fecondo, The detection of influenza A and B viruses in clinical specimens using a quartz crystal microbalance. J. Virol. Meth. 162 (2009) 14-21.

26. M.F. Diouani, Helali, I. Hafaid, W.M. Hassen, M.A. Snoussi, A. Ghram, N. JaffrezicRenault, A. Abdelghani, Miniaturized biosensor for avian influenza virus detection, Mater. Sci. Eng. C 28 (2008) 580-583. 


\section{Figure captions}

Scheme 1. Steps of immunosensor construction.

Fig. 1. Typical electrochemical impedance spectra obtained for GDE modified with BSA/scFv/AuNPs/TBBT/GDE (a) in buffer solution and after treatment with (b) 4, (c) 8, (d) 12, (e) 16, (f) $20 \mathrm{pg} / \mathrm{mL} \mathrm{A}$ ) "Qinghai" and B) "Netherlands". The measuring conditions: a bias potential of $0.17 \mathrm{~V}$; a frequency range from $0.1 \mathrm{~Hz}$ to $10 \mathrm{kHz}$. Solution composition: $1 \mathrm{mM} \mathrm{K}\left[\mathrm{Fe}(\mathrm{CN})_{6}\right]$ / $\mathrm{K}_{4}\left[\mathrm{Fe}(\mathrm{CN})_{6}\right]$, $0.1 \mathrm{M}$ PBS $\mathrm{pH}$ 7.4. Circuit model used for fitting Nyquist plots in inset: $\mathrm{R}_{\mathrm{s}}-$ solution resistance, $\mathrm{R}_{\mathrm{et}}$ - electron transfer resistance, and CPE-constant phase element.

Fig. 2. The relationship of $\left(\mathrm{R}_{\mathrm{i}}-\mathrm{R}_{0}\right) / \mathrm{R}_{0}[\%]$ vs. concentrations $\mathrm{C}[\mathrm{pg} / \mathrm{mL}]$ of: (•) "Qinghai"; (४) "HA/Nde" and ( $\boldsymbol{\Delta})$ "Netherlands" proteins. $\mathrm{R}_{0}$ is the electron transfer resistance of a fully modified electrode measured in PBS buffer before antigen application and $R_{i}$ is the electron transfer resistance of fully modified electrode measured in 0.1 M PBS buffer with the given concentration of an antigen $(\mathrm{n}=5)$.

Fig. 3. Typical square wave voltammograms obtained for SPGEs modified with BSA/scFv/AuNPs/TBBT/GDE (a) in buffer solution and after treatment with (b) 1, (c) 4, (d) $8 \mathrm{pg} / \mathrm{mL}$ A) "Qinghai" and B) "Netherlands". The measuring conditions: square wave frequency of $25 \mathrm{~Hz}$ and amplitude of $0.05 \mathrm{~V}$. Solution composition: $1 \mathrm{mM} \mathrm{K}_{3}\left[\mathrm{Fe}(\mathrm{CN})_{6}\right] / \mathrm{K}_{4}\left[\mathrm{Fe}(\mathrm{CN})_{6}\right], 0.1 \mathrm{M}$ PBS pH 7.4.

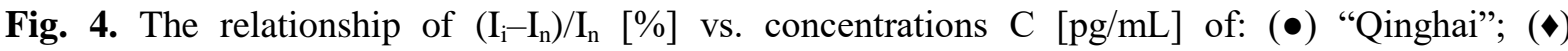
"HA/Nde" and ( $\mathbf{\Delta}$ ) "Netherlands" proteins. $\mathrm{I}_{0}$ is the value of peak current of fully modified electrode measured in pure PBS buffer before antigen application and $\mathrm{I}_{\mathrm{i}}$ is the value of the peak current of the fully modified electrode measured in 0.1 M PBS buffer with the given concentration of an antigen ( $\mathrm{n}$ $=5)$. 


\title{
Supporting Information
}

\section{An electrochemical immunosensor based on a 4,4'- thiobisbenzenethiol self-assembled monolayer for the detection of hemagglutinin from avian influenza virus H5N1}

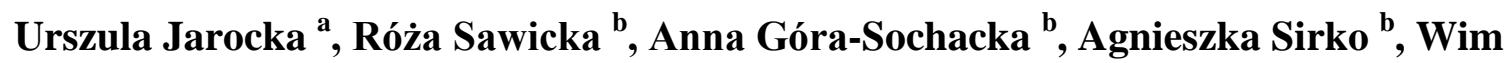 \\ Dehaen $^{\text {c, Jerzy Radecki }}{ }^{\text {a }}$, Hanna Radecka ${ }^{\text {a,* }}$ \\ ${ }^{\text {a }}$ Institute of Animal Reproduction and Food Research, Polish Academy of Sciences, Tuwima 10, 10- \\ 748 Olsztyn, Poland \\ ${ }^{\mathrm{b}}$ Institute of Biochemistry and Biophysics, Polish Academy of Sciences, Pawińskiego 5A, 02-106 \\ Warsaw, Poland \\ ${ }^{c}$ University of Leuven, Department of Chemistry, Celestijnenlaan 200F, B-3001 Leuven, Belgium \\ * Corresponding authors. Tel.: +48-89-523-4636; Fax: +48-89-524-0124. \\ E-mail address: h.radecka@pan.olsztyn.pl.
}

\section{Experimental}

\subsection{Reagents and materials}

Gold colloidal nanoparticles (AuNPs, $17-23 \mathrm{~nm}$ in diameter), potassium ferro- and ferricyanides, phosphate buffer saline (PBS) components (137 mM NaCl, $2.7 \mathrm{mM} \mathrm{KCl}, 1.8$ $\mathrm{mM} \mathrm{Na}_{2} \mathrm{HPO}_{4}, 10 \mathrm{mM} \mathrm{K \textrm {K } _ { 2 }} \mathrm{PO}_{4}$ ) were supplied by Sigma-Aldrich (Poznań, Poland). 4,4'Thiobisbenzenethiol (TBBT) was obtained from the University of Leuven (Belgium). Alumina slurry 0.3 and $0.05 \mu \mathrm{m}$ was purchased from Buehler (Lake Bluff, IL, USA). Sulphuric acid, potassium hydroxide, ethanol and methanol were obtained from POCh (Gliwice, Poland). Bovine serum albumin (BSA) was purchased from Invitrogen Life Technologies (Darmstadt, Germany). The single chain variable fragment (scFv) of anti-H5 
hemagglutinin mouse monoclonal antibody mAb6-9-1 was obtained from the Institute of Biochemistry and Biophysics (Warsaw, Poland) [16]. Two His-tagged recombinant variants of the H5 hemagglutinin were used in this work. The "HA/Nde" protein is based on the sequence of A/swan/Poland/305-135V08/2006 (EpiFlu Database Acc no. EPI156789), covers region of 17-340 residues (corresponding to the $\mathrm{H} 1$ subunit) and was produced in Escherichia coli cells. The "Qinghai" protein, (based on the sequence of A/bar headed goose/Qinghai/12/2005 (Genbank Acc no. ABE68927); covers region of 17-530 residues and was produced in mammalian cells. A His-tagged recombinant hemagglutinin variant of H7N7 virus: "Netherlands" was used as the negative control. The "Netherlands" protein is based on the sequence of A/chicken/Netherlands/1/03 (Genbank Acc no. AY338459) and covers the region of 17-527 amino acids. The "Qinghai" and "Netherlands" proteins were purchased from Immune Technology (New York, NY, USA), while the "HA/Nde" protein was obtained from the Institute of Biochemistry and Biophysics (Warsaw, Poland).

All aqueous solutions were prepared using Milli-Q water, with resistivity $18.2 \mathrm{M} \Omega \cdot \mathrm{cm}$ (Millipore, Darmstadt Germany). Reagents and solvents were of analytical grade and were used without further purification. Experiments were carried out at room temperature unless stated otherwise.

\subsection{Preparation of the immunosensor based on the gold disc electrodes}

The gold disc electrodes (GDEs, $2 \mathrm{~mm}$ diameter) were obtained from Bioanalytical System (BAS, West Lafayette, IN, USA). The GDE after washing with methanol and Milli-Q water were polished in alumina slurries (Alpha and Gamma Micropolish) with particles size of 0.3 and $0.05 \mu \mathrm{m}$ on microcloth polishing pads (BAS) for 5 minutes each. Afterwards they were carefully washed with Milli-Q water. Then, electrochemical cleaning was performed by cyclic voltammetry $(\mathrm{CV})$. At first they were dipped in $0.5 \mathrm{M}$ potassium hydroxide solution and swept with a potential between $-0.4 \mathrm{~V}$ and $-1.2 \mathrm{~V}$ against a silver chloride reference electrode $(\mathrm{Ag} / \mathrm{AgCl})$ and a platinum wire counter electrode with scan rate of $0.1 \mathrm{~V} / \mathrm{s}$, number of cycles: 3, 50 and 10. Next, the electrodes were cleaned in $0.5 \mathrm{M}$ sulphuric acid solution in the potential window between $-0.3 \mathrm{~V}$ and $+1.5 \mathrm{~V}$, number of cycles: 3,10 and 3 . Before modification, the surfaces of the electrodes were refreshed in $0.5 \mathrm{M}$ potassium hydroxide solution for 10 cycles. After finishing the electrochemical cleaning each electrode was rinsed with Milli-Q water and stored in water (for several minutes, until the next step) to avoid contamination from air. All solutions were deoxygenated by purging with nitrogen (ultra pure 6.0, Air Products, Warsaw, Poland) for 10 minutes. 
The clean GDEs were washed repeatedly with Milli-Q water and ethanol. Then, they were immersed for $1 \mathrm{~h}$ in $1 \mathrm{mM}$ TBBT in ethanol. The tubes containing the electrodes and TBBT were sealed with a Teflon tape and parafilm to avoid solvent evaporation. Subsequently the electrodes were rinsed with ethanol and Milli-Q water. These electrodes with formed TBBT self-assembled monolayer (SAM) were fixed upside down and $10 \mu \mathrm{L}$ droplets of AuNPs were spotted on each gold surface. The tubes containing electrodes were sealed with parafilm and stored in $+4^{\circ} \mathrm{C}$ for $18 \mathrm{~h}$. After incubation, the electrodes were rinsed with Milli-Q water and 0.1 M PBS, pH 7.4. Next, $10 \mu \mathrm{L}$ droplets of $1 \mu \mathrm{g} / \mathrm{mL}$ scFv in PBS buffer were aliquoted onto the surface of each electrode. The tubes with electrodes were again sealed with parafilm and incubated for $1 \mathrm{~h}$. Then, the electrodes were carefully rinsed with PBS buffer. BSA (in 0.1 M PBS, pH 7.4) in a concentration of $1 \%(\mathrm{~m} / \mathrm{v}$ ) was used for blocking of unspecific binding. As in the prior steps, $10 \mu \mathrm{L}$ droplets were spotted on each electrode and stored for $0.5 \mathrm{~h}$. Finally, the electrodes were rinsed with 0.1 M PBS. Fully modified electrodes were kept in a refrigerator $\left(+4^{\circ} \mathrm{C}\right)$ in $0.1 \mathrm{M} \mathrm{PBS}$ buffer, $\mathrm{pH} 7.4$ until use, no longer than one day.

\subsection{Electrochemical measurements}

Electrochemical measurements with conventional three-electrode configuration were performed using a potentiostat-galvanostat AutoLab (Eco Chemie, Utrecht, Netherlands). Working electrodes were polycrystalline gold discs of $2 \mathrm{~mm}$ diameter (BioAnalytical System, BAS, West Lafayette, IN). All potentials were measured versus an $\mathrm{Ag} / \mathrm{AgCl}$ reference electrode, and a platinum wire was used as a counter electrode. Electrochemical measurements with SPGEs were performed using a $\mu$ Stat 400 potentiostat/galvanostat (DropSens, Oviedo, Spain). Electrochemical experiments were performed in a solution comprised of 0.1 M PBS pH 7.4 and $\mathrm{K}_{3}\left[\mathrm{Fe}(\mathrm{CN})_{6}\right] / \mathrm{K}_{4}\left[\mathrm{Fe}(\mathrm{CN})_{6}\right](0.5 \mathrm{mM}$ each). In the cyclic voltammetry $(\mathrm{CV})$ the potential was cycled from 0.6 to $-0.2 \mathrm{~V}$ with scan rate $0.1 \mathrm{~V} / \mathrm{s}$. The electrochemical impedance spectroscopy (EIS) was recorded within a frequency range of 0.1 $\mathrm{Hz}$ to $10 \mathrm{kHz}$ at the formal potential of the redox couple $\left[\mathrm{Fe}(\mathrm{CN})_{6}\right]^{3-/ 4-}(0.17 \mathrm{~V})$ with ac amplitude of $10 \mathrm{mV}$. Obtained spectra were fitted by AutoLab software in order to obtain values of electron transfer resistance $\left(\mathrm{R}_{\mathrm{i}}\right)$. The electrode responses were expressed as: $\left(\mathrm{R}_{\mathrm{i}}-\right.$ $\mathrm{R}_{0}$ ) / $\mathrm{R}_{0}$ where $\mathrm{R}_{0}$ means the electron transfer resistance of a fully modified electrode measured in pure PBS buffer before His-tagged recombinant proteins detection, $R_{i}$ means the electron transfer resistance of a fully modified electrode measured in PBS containing a particular concentration of the detected proteins. OSWV was performed with a potential from 
$0.55 \mathrm{~V}$ to $-0.25 \mathrm{~V}$ with a square wave frequency of $25 \mathrm{~Hz}$ and an amplitude of $0.05 \mathrm{~V}$. The electrode responses were expressed as: $\left(\mathrm{In}-\mathrm{I}_{0}\right) / \mathrm{I}_{0}$ where $\mathrm{I}_{\mathrm{n}}$ is the peak current measured in the presence of His-tagged recombinant proteins and $\mathrm{I}_{0}$ the peak current before applying the target proteins.

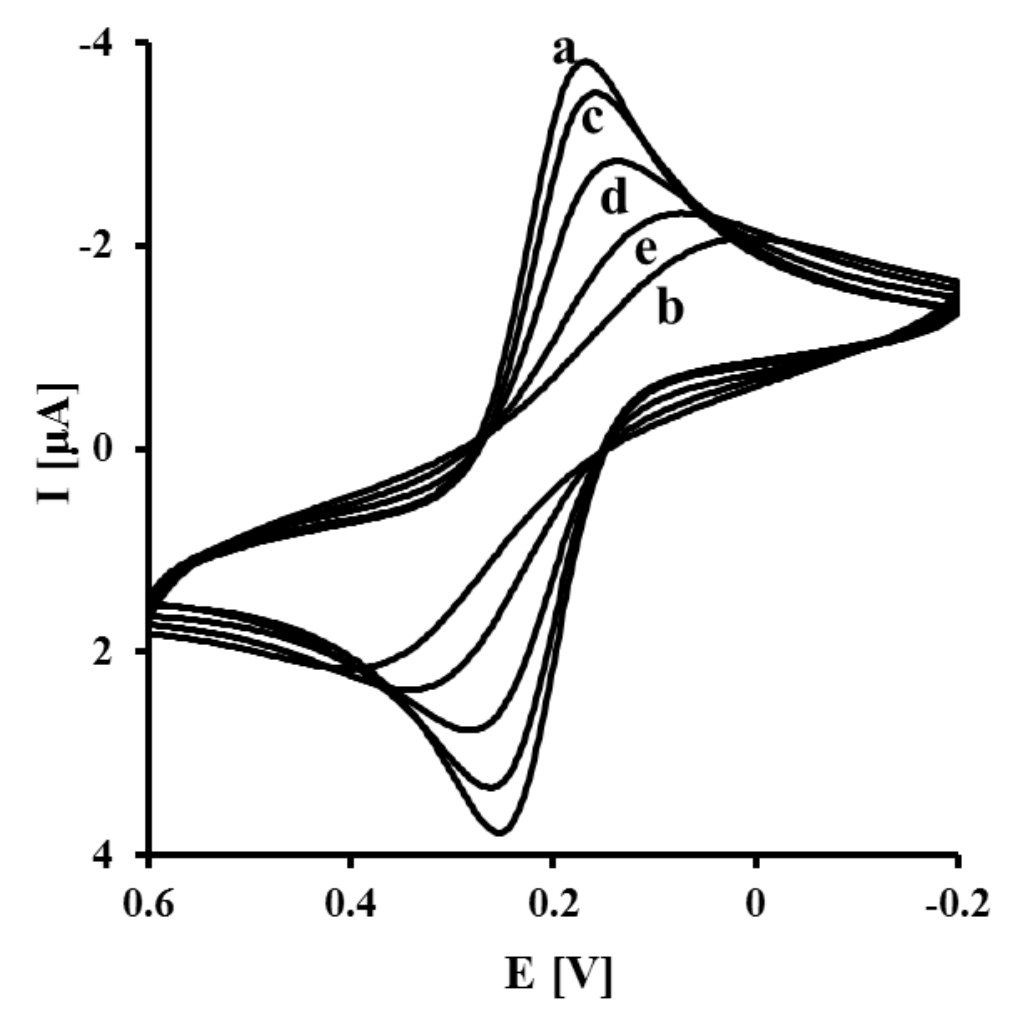

Fig. S1. Typical cyclic voltammograms of: (a) bare GDE; (b) TBBT modified electrode; (c) AuNPs/TBBT modified electrode; (d) scFv/AuNPs/TBBT modified electrode; (e) BSA/scFv/AuNPs/TBBT modified electrode. Solution composition: $1 \mathrm{mM} \mathrm{K}_{3}\left[\mathrm{Fe}(\mathrm{CN})_{6}\right] / \mathrm{K}_{4}\left[\mathrm{Fe}(\mathrm{CN})_{6}\right]$, 0.1 M PBS pH 7.4. The measuring conditions: three electrode configurations-Au working electrode, $\mathrm{Ag} / \mathrm{AgCl}$ reference electrode, and $\mathrm{Pt}$ counter electrode; scan rate $100 \mathrm{mV} / \mathrm{s}$. 


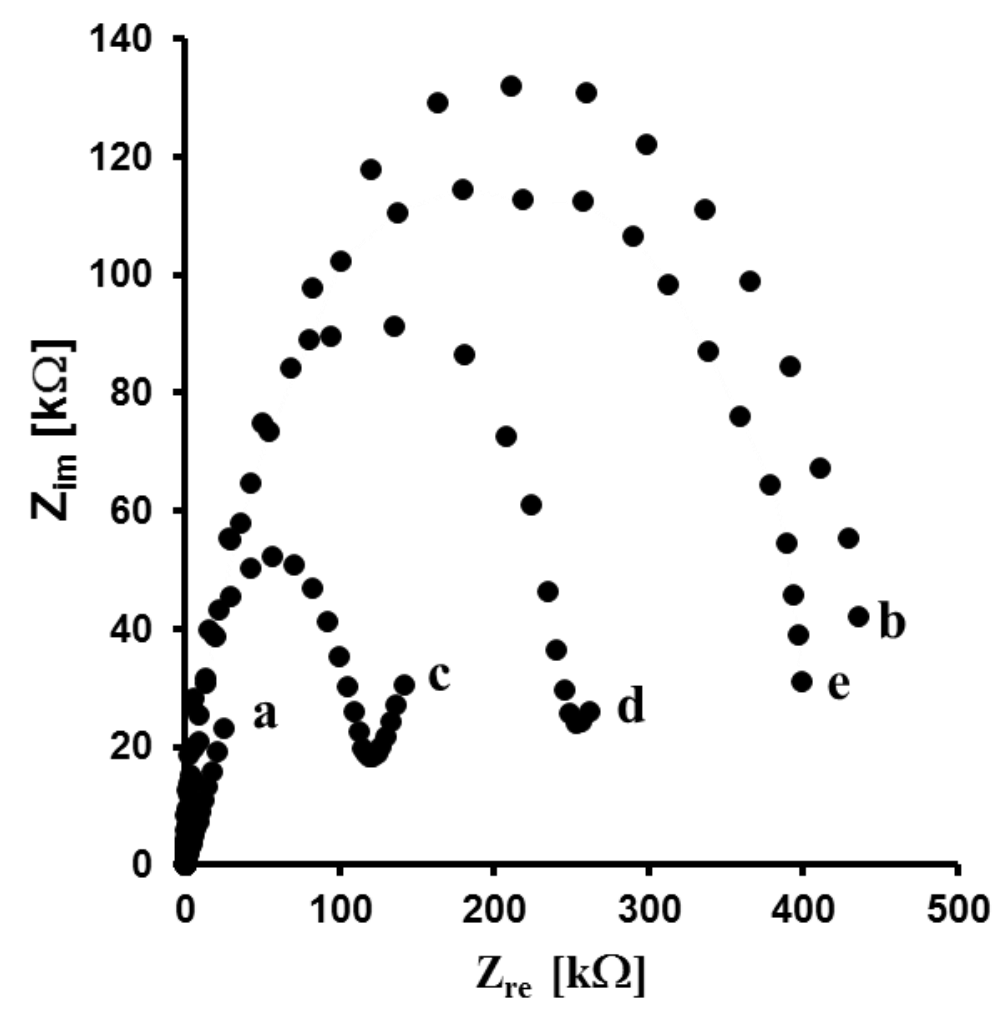

Fig. S2. Typical electrochemical impedance spectra of: (a) bare GDE; (b) TBBT modified electrode; (c) AuNPs/TBBT modified electrode; (d) scFv/AuNPs/TBBT modified electrode; (e) BSA/scFv/AuNPs/TBBT modified electrode. Solution composition: $1 \mathrm{mM} \mathrm{K}_{3}\left[\mathrm{Fe}(\mathrm{CN})_{6}\right] / \mathrm{K}_{4}\left[\mathrm{Fe}(\mathrm{CN})_{6}\right]$, $0.1 \mathrm{M}$ PBS $\mathrm{pH}$ 7.4. The measuring conditions: three electrode configurations-GC working electrode, $\mathrm{Ag} / \mathrm{AgCl}$ reference electrode, and $\mathrm{Pt}$ counter electrode; a bias potential of $0.17 \mathrm{~V}$; the frequency range from $0.1 \mathrm{~Hz}$ to $10 \mathrm{kHz}$. 

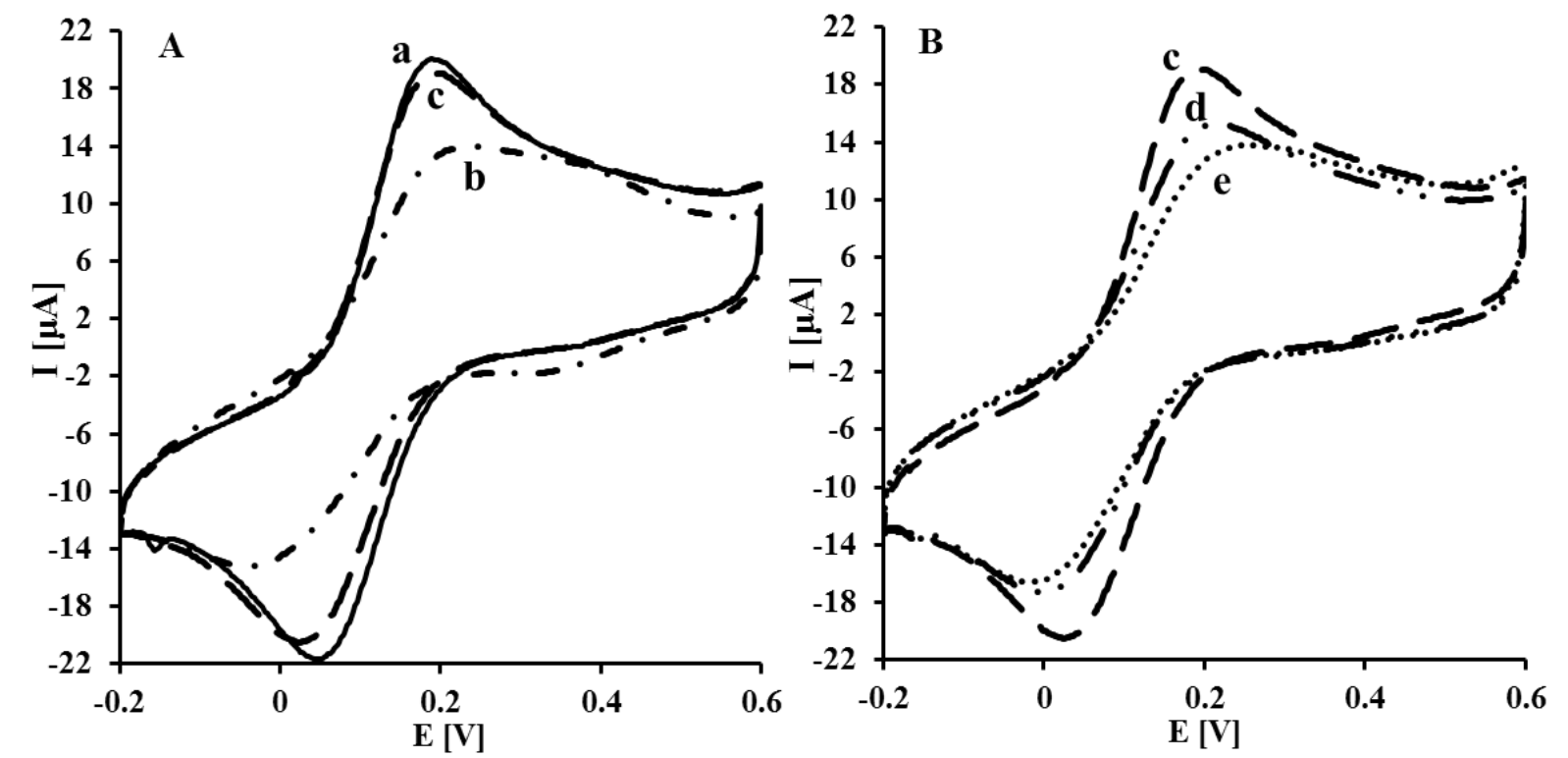

Fig. S3. Typical cyclic voltammograms of: (a) bare SPGE; (b) TBBT modified electrode; (c) AuNPs/TBBT modified electrode; (d) scFv/AuNPs/TBBT modified electrode; (e) BSA/scFv/AuNPs/TBBT modified electrode. Solution composition: $1 \mathrm{mM} \mathrm{K}_{3}\left[\mathrm{Fe}(\mathrm{CN})_{6}\right] / \mathrm{K}_{4}\left[\mathrm{Fe}(\mathrm{CN})_{6}\right]$, $0.1 \mathrm{M}$ PBS $\mathrm{pH}$ 7.4. The measuring conditions: three electrode configurations-Au working and counter electrodes, $\mathrm{Ag}$ reference electrode; scan rate $100 \mathrm{mV} / \mathrm{s}$. 


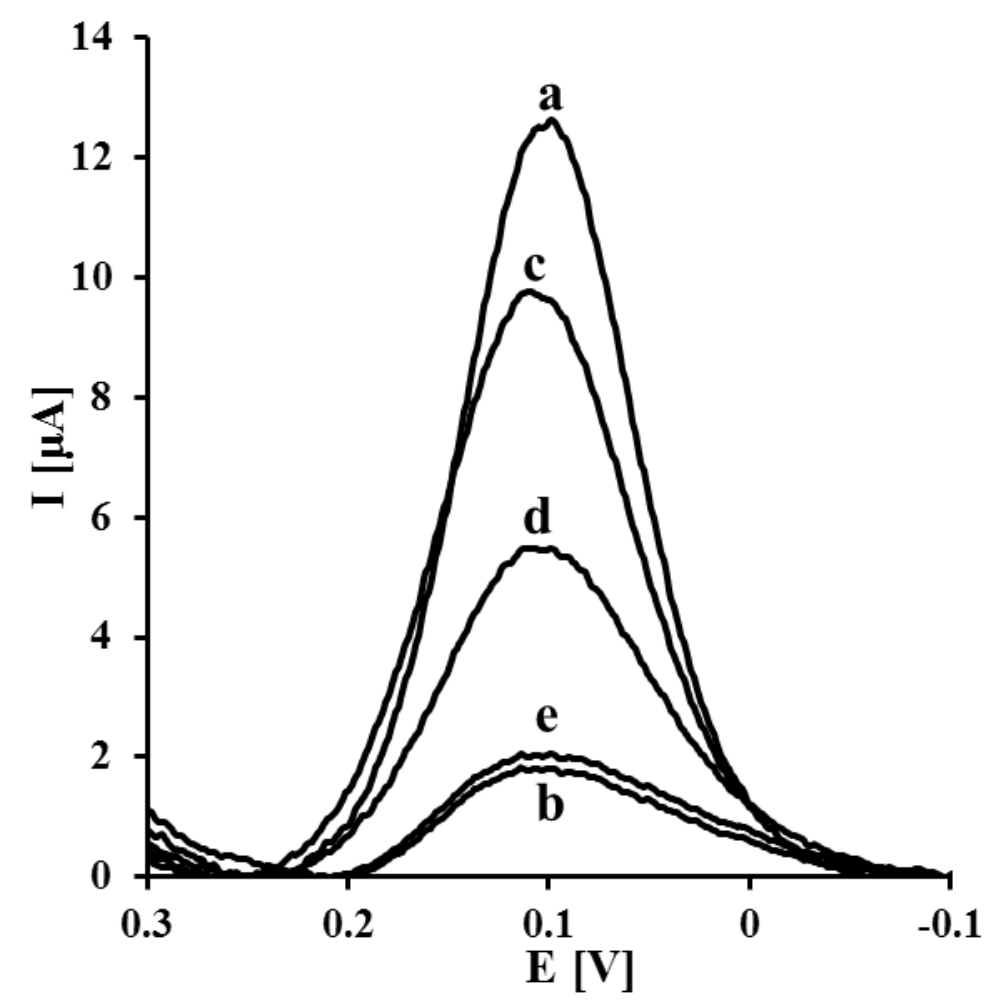

Fig. S4. Typical square wave voltammograms of: (a) bare SPGE; (b) TBBT modified electrode; (c) AuNPs/TBBT modified electrode; (d) scFv/AuNPs/TBBT modified electrode; (e) BSA/scFv/AuNPs/TBBT modified electrode. Solution composition: $1 \mathrm{mM} \mathrm{K}_{3}\left[\mathrm{Fe}(\mathrm{CN})_{6}\right] / \mathrm{K}_{4}\left[\mathrm{Fe}(\mathrm{CN})_{6}\right]$, $0.1 \mathrm{M}$ PBS $\mathrm{pH}$ 7.4. The measuring conditions: three electrode configurations-Au working and counter electrodes, Ag reference electrode; square wave frequency of $25 \mathrm{~Hz}$ and amplitude of $0.05 \mathrm{~V}$. 


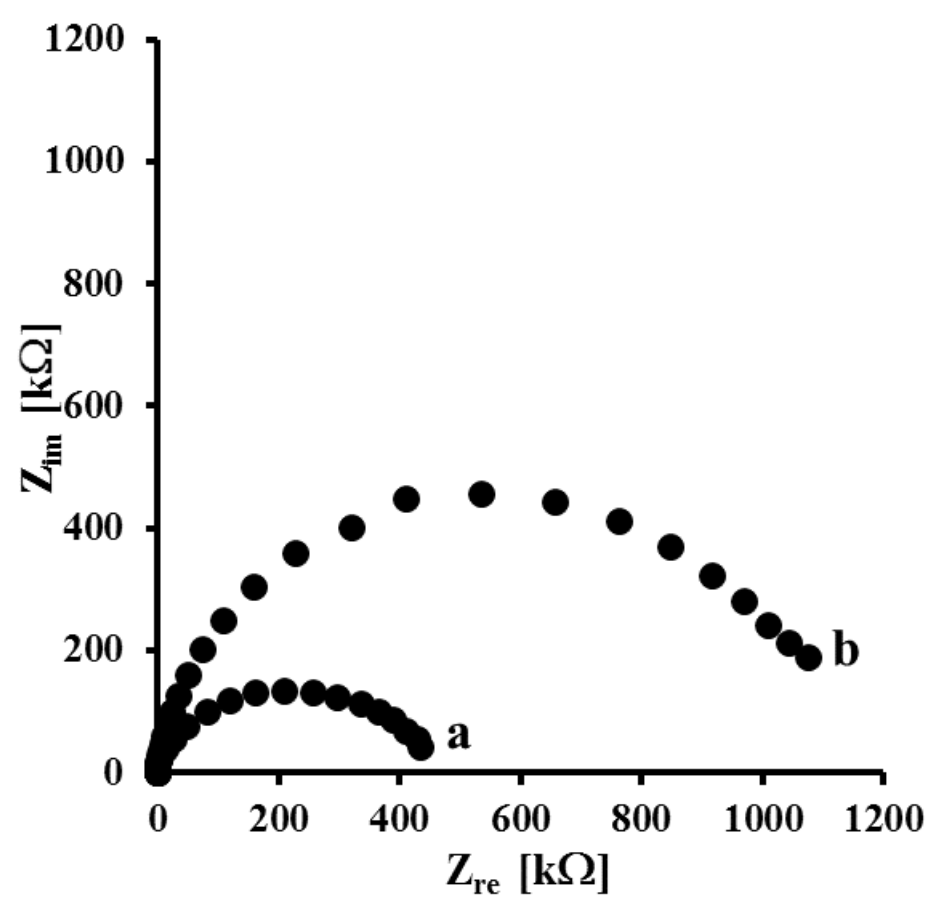

Fig. S5. Typical electrochemical impedance spectra of (a) TBBT modified electrode; (b) HDT modified electrode. The measuring conditions: a bias potential of $0.17 \mathrm{~V}$; a frequency range from 0.1 $\mathrm{Hz}$ to $10 \mathrm{kHz}$. Solution composition: $1 \mathrm{mM} \mathrm{K}_{3}\left[\mathrm{Fe}(\mathrm{CN})_{6}\right] / \mathrm{K}_{4}\left[\mathrm{Fe}(\mathrm{CN})_{6}\right]$, 0.1 M PBS pH 7.4. 